\title{
Atributos de fertilidade dos solos as margens do Rio Paraguai, Pantanal de Cáceres/MT
}

A natureza do material de origem e os processos de deposição/sedimentação, decorrente do ciclo natural de inundação e seca, conferem aos solos do Pantanal características diferenciadas. O objetivo deste trabalho foi avaliar os atributos de fertilidade em áreas de vegetação nativa as margens do rio Paraguai, Pantanal de Cáceres/Mato Grosso. Foram coletadas amostras de solos deformadas na profundidade de 0,0 a 0,20 m para análises química e granulométrica, e amostras indeformadas na profundidade de 0,0 a 0,10 m para análise da densidade do solo (Ds), em doze áreas entre o município de Cáceres-MT e a Estação Ecológica de Taiamã, apresentando as seguintes classes de solo: Argissolo, Gleissolo, Neossolo e Planossolo. As análises químicas de fertilidade dos solos foram realizadas em todas as amostras coletadas, constando: $\mathrm{pH}$ em H2O, pH SMP, teores de $\mathrm{P}, \mathrm{K}+, \mathrm{Ca} 2+, \mathrm{Mg} 2+$, acidez trocável (Al3+), acidez potencial (H+Al) e matéria orgânica (M.O), sendo calculado a soma de bases (SB), a capacidade de troca de cátions (CTC pH 7,0 e CTC efetiva), a saturação por bases do solo (V) e a saturação por alumínio $(\mathrm{m})$. Na análise física, foram determinadas a granulometria e a densidade do solo (Ds). Através da análise de regressão foram estabelecidas equações entre a acidez potencial (H+Al) determinada por acetato de cálcio tamponado a pH 7,0 e os valores do pH SMP visando obter uma equação que melhor descreva a relação entre essas duas variáveis, para estimar a acidez potencial. Entre as áreas amostradas, a área com presença de Neossolo apresentou as melhores características em relação a fertilidade natural do solo, entretanto a elevada acidez trocável foi verificada na maioria dos solos, pode causar restrições ao crescimento e desenvolvimento das plantas nas margens do rio Paraguai. A acidez potencial desses solos poderá ser estimada pelo método do pH SMP através da equação $\mathrm{H}+\mathrm{Al}=24,1861-3,3144 \times \mathrm{pH}$ SMP.

Palavras-chave: Áreas Úmidas; Atributos Físico-Químicos; H+Al.

\section{Soil fertility attributes on the banks of the Paraguay River, Pantanal de Cáceres/MT}

The nature of the source material and the processes of deposition/sedimentation, due to the natural cycle of flooding and drought, confers on Pantanal soils different characteristics. The objective of this study was to evaluate the fertility attributes in areas of native vegetation on the margins of the Paraguay river Pantanal of Caceres, state of Mato Grosso. Deformed samples from soils were collected at depths of 0.0 to 0.20 m for chemical and granulometric analyzes undeformed samples in the depth of 0.0 to $0.10 \mathrm{~m}$ for analysis of the soil bulk density, in twelve areas between the municipality of Caceres-MT and the Ecological Station of Taiama, presenting the following soil classes: Argisol, Gleysol, Neosol and Planosol. The chemical analyzes of soil fertility were performed on all the samples collected, consisting: $\mathrm{pH}$ in water, $\mathrm{pH}$ SMP, contents of $\mathrm{P}, \mathrm{K}+, \mathrm{Ca} 2+, \mathrm{Mg} 2+$, exchangeable acidity (Al3+), potential acidity ( $\mathrm{H}+\mathrm{Al})$ and organic matter, being calculated the sums of base (SB), cation exchange capacity (CEC pH7.0 and effective CEC), base saturation (V) and aluminum saturation (m). In physical analysis, were determined the granulometry and soil bulk density (Ds). Through the regression analysis equations were established between potential acidity $(\mathrm{H}+\mathrm{Al})$ determined by calcium acetate buffered at $\mathrm{pH} 7.0$ and $\mathrm{pH}$ SMP values aiming to obtain an equation that best describes the relationship between these two variables, to estimate the potential acidity. Among the areas sampled, the area with presence of Neosol were verified the best characteristics in relation to natural fertility however, high exchangeable acidity was verified in most soils, causing constraints on growth and development of plants. The potential acidity of these soils can be estimated by the $\mathrm{pH}$ SMP method through equation $\mathrm{H}+\mathrm{Al}=24.1861-3.3144 \mathrm{pH}$ SMP.

Keywords: Wetlands; Physical-Chemical Attributes; $\mathrm{H}+\mathrm{Al}$.

\section{Topic: Ciências do Solo}

Reviewed anonymously in the process of blind peer.

\section{Geilson Xavier Rocha}

Universidade do Estado de Mato Grosso, Brasil

http://lattes.cnpq.br/14639046937777343

gxr.3agro@gmail.com

Maria Aparecida Pereira Pierangeli (iD

Universidade do Estado de Mato Grosso, Brasil

http://lattes.cnpq.br/4330841132184376

http://orcid.org/0000-0001-6453-080X

mapp@unemat.br

Mayara Cristina Santos Marques

Universidade do Estado de Mato Grosso, Brasil

http://lattes.cnpq.br/3497252447430497

mayaracsmarques@gmail.com

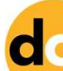

DOI: 10.6008/CBPC2179-6858.2018.004.0008
Received: 10/04/2018

Approved: 24/05/2018
Referencing this:

ROCHA, G. X.; PIERANGELI, M. A. P.; MARQUES, M. C. S.. Atributos de fertilidade dos solos as margens do Rio Paraguai, Pantanal de Cáceres/MT. Revista Ibero Americana de Ciências Ambientais, v.9, n.4, p.99-110, 2018. DOI: http://doi.org/10.6008/CBPC21796858.2018 .004 .0008 


\section{INTRODUÇÃO}

O Pantanal, situado no interior da Bacia do Alto Paraguai, é uma das maiores extensões de áreas alagáveis do mundo, ocupando uma área aproximada de 200 mil km², dos quais $70 \%$ no Brasil, 20\% na Bolívia e 10\% no Paraguai. Apresenta uma extensão de cerca de 150 mil $\mathrm{Km}^{2}$ inseridos no território nacional brasileiro, nos estados do Mato Grosso e Mato Grosso do Sul (HARRIS et al., 2005).

Inúmeras intervenções vem sendo feitas no Pantanal, motivadas por uso agrícola, pecuária, turismo e hidrovia para o transporte de cargas. O agravante é que tais usos são feitos sem um conhecimento adequado e sem planejamento que possa minimizar as alterações nas propriedades do solo e seus efeitos sobre o rio Paraguai. Quando os ecossistemas são alterados, o equilíbrio dinâmico é quebrado, trazendo assim, prejuízos para os serviços ecossistêmicos da paisagem e para a qualidade do solo (PRAGANA et al., 2012).

Os atributos do solo têm sido usados historicamente como servidores de qualidade do solo (ANDREWS et al., 2002), estando a qualidade, relacionada às características intrínsecas do solo, as interações com o ecossistema e ao tipo de uso/ocupação da terra. Cardoso et al. (2010) verificaram que a conversão de florestas em pastagens promoveu redução nos estoques de carbono orgânico e carbono microbiano no solo, do Pantanal da Nhecolândia, promovendo consequentemente alterações nas características físicas, químicas e biológicas do solo.

Os solos na paisagem podem ser vistos sob a ótica da variabilidade espaço-temporal de seus atributos e sob a perspectiva de processos dinâmicos (SOMMER, 2006), sendo importante a compreensão mais abrangente do solo na paisagem, o qual apresenta funções e serviços ecossistêmicos de proteção (KEESTRA et al., 2012) do meio ambiente. A natureza do material de origem e o regime de inundações periódicas, conferem aos solos dessa região características diferenciadas, como alta saturação de alumínio e textura variável em decorrência do tipo de sedimentos depositados (FERNANDES et al., 2007), adição ou perda de materiais inorgânicos e orgânicos.

Estudos sobre os solos do Pantanal tem buscado compreender os processos de migração, dispersão e concentração de elementos químicos no seu perfil, por meio de análise geoquímica dos solos de diferentes ambientes (CORINGA et al., 2014). Santos et al. (2013) evidenciaram a importância de se conhecer as propriedades pedológicas dos solos, pois as mesmas podem favorecer ou não o processo de erosão das margens do rio, bem como interferir no canal e conformação das margens.

Entretanto, ainda são pouco conhecidas as variações nos atributos dos solos, em sistemas complexos, como o Pantanal, no qual deve se ter como premissas imprescindíveis a compreensão dos processos ecológicos responsáveis pela sua produtividade e biodiversidade, e fundamentalmente, o conhecimento sobre como os componentes bióticos e abióticos se inter-relacionam (CARDOSO et al., 2016).

No Brasil, a criação de bancos de dados de solos ainda é incipiente e sabe-se pouco sobre as áreas de formações vegetais nativas e a fertilidade natural dos solos (SKORUPA et al., 2012). A falta destas informações pode levar a ações inadequadas e insustentáveis, aumentando o risco de degradação ambiental 
e perda da biodiversidade (MULDER et al., 2011) em ambientes naturais. Diante disso, o objetivo deste trabalho foi avaliar os atributos relativos a fertilidade do solo em áreas de vegetação nativa as margens do rio Paraguai, Pantanal de Cáceres/Mato Grosso.

\section{MATERIAIS E MÉTODOS}

As áreas de estudo encontram-se localizadas às margens do rio Paraguai, Pantanal de Cáceres/MT, no trecho entre o município de Cáceres e a Estação Ecológica de Taiamã (Figura 1), onde foram amostradas áreas de solos passíveis ou não de inundação.

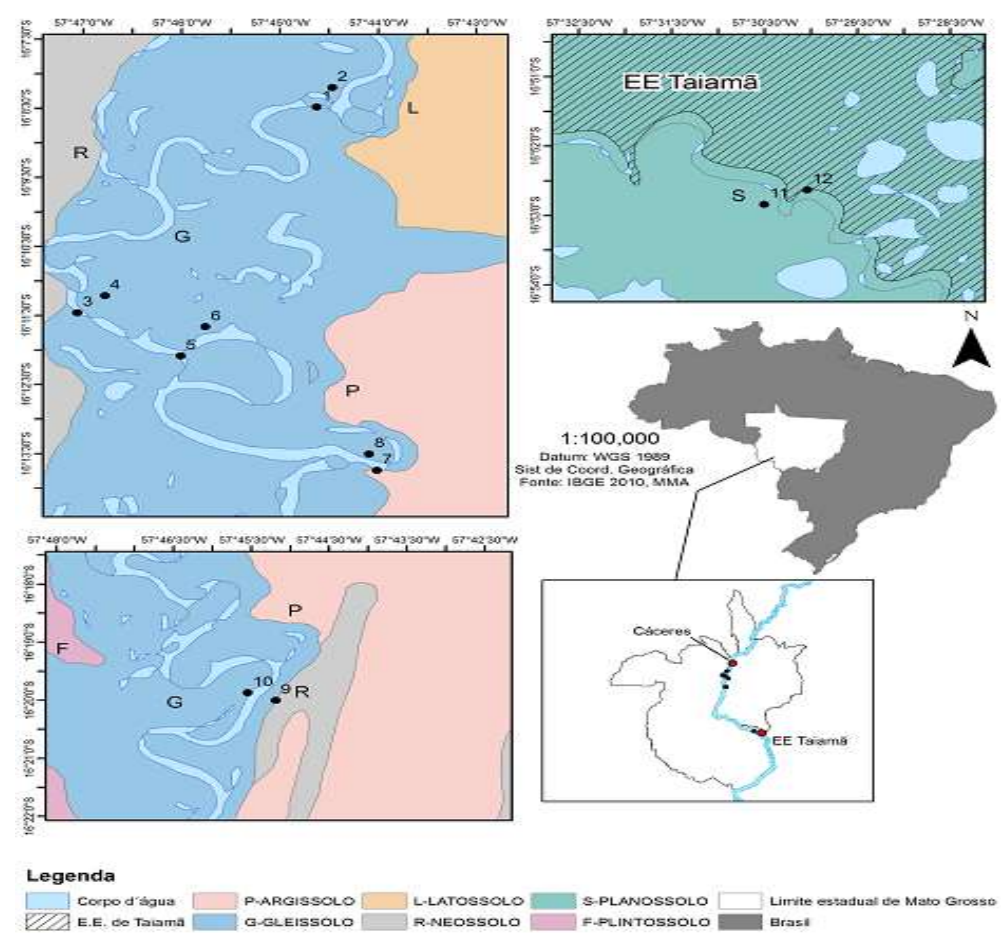

Figura 1: Localização e mapa pedológico das áreas de estudo as margens do rio Paraguai, Pantanal de Cáceres/MT. Fonte: IBGE; MMA (2010).

O Pantanal de Cáceres/MT constitui uma das onze sub-regiões que compõe o Pantanal brasileiro, possuindo uma área estimada de $12.456 \mathrm{Km}^{2}$, ocupando aproximadamente $9,01 \%$ da planície pantaneira (SILVA et al., 1998). O clima, de acordo com a classificação de Koppen é do tipo Aw (quente e úmido) e a precipitação anual é de $1.500 \mathrm{~mm}$. A vegetação da região as margens do rio Paraguai é classificada como floresta estacional semi-decidual aluvial (IBGE, 2012) sendo uma formação encontrada com grande frequência na depressão Pantaneira.

Os solos das áreas de estudo foram identificados através de mapa (Figura 1), sendo os mesmos classificados em Argissolo, Gleissolo, Neossolo e Planossolo (1 ${ }^{\circ}$ nível categórico) de acordo com o Sistema Brasileiro de Classificação de Solos - SiBCS (EMBRAPA, 2013). Das áreas de estudo amostradas, a área com presença de Neossolo localiza-se em uma província serrana, não passível de inundação.

As amostras de solo foram coletadas no início do mês de dezembro, período de chuva, em doze áreas de vegetação nativa às margens do rio Paraguai, Pantanal de Cáceres - Mato Grosso, selecionadas de acordo com a classe de solo. Em cada área foram coletadas amostras de solo a uma distância aproximada de $20 \mathrm{~m}$ 
das margens do rio Paraguai, sendo obtidas duas amostras de solo por área com pontos distanciados entre si em 20 m (repetições de campo).

Foram coletadas amostras de solo na profundidade de 0,0-0,20 m utilizando-se trado holandês de aço inoxidável para análises químicas e granulométricas. Amostras indeformadas de solo na profundidade de 0,0-0,10 m foram coletas com anéis volumétricos para análise da densidade do solo. Em todos os pontos de amostras de solo foram obtidas as coordenadas geográficas e a altitude com dispositivo de GPS - Sistema de Posicionamento Global.

As amostras de solo coletadas para análises químicas foram secas ao ar, destorroadas, homogeneizadas, identificadas e destinadas ao Laboratório de química do solo da ESALQ-USP, onde foram realizados os seguintes procedimentos: cálcio $\left(\mathrm{Ca}^{2+}\right)$ e magnésio $\left(\mathrm{Mg}^{2+}\right)$ extração por $\mathrm{KCl} 1 \mathrm{~mol} \mathrm{~L}^{-1} \mathrm{e}$ determinação em espectrofotômetro de absorção atômica; acidez trocável $\left(\left.A\right|^{3+}\right)$ extração por $\mathrm{KCl} 1 \mathrm{~mol} \mathrm{~L}^{-1}$ e determinação por titulação; acidez potencial (H+Al) extração por acetato de cálcio $0,5 \mathrm{~mol} \mathrm{~L}^{-1}$ a pH $7,0 \mathrm{e}$ determinação por titulometria; fósforo $(P)$ extração por Mehlich $^{1}$ e determinação por colorimetria; potássio $\left(\mathrm{K}^{+}\right)$extração por Mehlich ${ }^{1}$ e determinação em espectrofotômetro de emissão atômica; pH em $\mathrm{H}_{2} \mathrm{O}$ (EMBRAPA, 1999); e a matéria orgânica (M.O.) extração por solução de dicromato em ácido sulfúrico e determinação por colorimetria (RAIJ et al., 2001). Posteriormente, foram calculadas a soma de bases (SB), a capacidade de troca de cátions (CTC), a porcentagem de saturação por bases do solo (V) e a porcentagem de saturação por alumínio $(\mathrm{m})$.

No laboratório de análise de solos da UNEMAT-Campus de Pontes e Lacerda, foram realizadas as análises físicas de granulometria e densidade do solo, sendo os procedimentos preconizados de acordo com a Embrapa (1999) e a determinação da acidez potencial ( $\mathrm{H}+\mathrm{Al}$ ) através de medidas do pH SMP associado ao $\mathrm{pH}$ em $\mathrm{H}_{2} \mathrm{O}$ (EMBRAPA, 2009). Foram estabelecidas equações entre a acidez potencial ( $\mathrm{H}+\mathrm{Al}$ ) determinada por acetato de cálcio tamponado a pH 7,0 e os valores de $\mathrm{pH}_{\text {SMP }}$ visando obter uma equação para cálculo da acidez potencial via $\mathrm{pH}_{\text {SMP. }}$ Os dados foram submetidos à análise estatística descritiva, análise de regressão e correlação de Pearson entre as variáveis acidez do solo e o pH sMP, utilizando a plataforma $R$ ( $R$ DEVELOPMENT CORE TEAM, 2015).

\section{RESULTADOS E DISCUSSÃO}

Os solos de áreas de vegetação nativa as margens do rio Paraguai, Pantanal de Cáceres-MT, apresentaram variações nos atributos químicos e físicos do solo. O conhecimento das propriedades do solo é muito importante para o manejo dos solos (CARVALHO JUNIOR et al., 2014) e do ambiente natural. De acordo com Kampf et al. (2012) ambientes sujeitos a longos tempos com saturação por água, pulso de inundação e má drenagem, sofrem grandes efeitos nas propriedades químicas e morfológicas do solo.

Através dos valores granulométricos verificados nas áreas de estudo (Tabela 1), pode-se observar maior teor médio de areia na camada superficial $(0,0-0,20 \mathrm{~m})$, em área com presença de Neossolo, apresentando assim um horizonte superficial de textura média (EMBRAPA, 2013). 
O predomínio da fração areia é característica geral dos Neossolos, os quais apresentam pequena expressão de atuação dos processos pedogenéticos, insuficiente para provocar modificações expressivas do material de origem, em razão da sua resistência ao intemperismo (SANTOS et al., 2012). Sendo assim, o alto teor de areia observado nessa área vem a ser proveniente do material de origem. Elevados teores de areia em solos das margens do rio Paraguai também foram observados por Sousa et al. (2015), corroborando com este trabalho. Os teores médios de argila e silte foram superiores na área de Planossolo (Tabela 1), apresentando respectivamente uma camada superficial de textura argilosa (EMBRAPA, 2013). Esses resultados podem ser em decorrência da deposição de maiores proporções de materiais síltico-argilosos em relação a areias inconsolidadas, provenientes das áreas ao entorno.

Tabela 1: Estatística descritiva referente aos resultados das análises físicas e determinação da classe de textura dos solos de áreas de nativa as margens do rio Paraguai, Pantanal de Cáceres/MT.

\begin{tabular}{|c|c|c|c|c|c|c|}
\hline & & Areia & Silte & Argila & \multirow{2}{*}{$\begin{array}{l}\text { Densidade } \\
\left(\mathrm{g} \mathrm{dm}^{-3}\right)\end{array}$} & \multirow[t]{2}{*}{ Classe de textura ${ }^{(1)}$} \\
\hline & & \multicolumn{3}{|c|}{------ $\left(\mathrm{g} \mathrm{kg}^{-1}\right)$------ } & & \\
\hline \multirow[t]{5}{*}{ Argissolo } & Média & 499,0 & 130,5 & 370,5 & 1,16 & Argilosa \\
\hline & Mediana & 499,0 & 130,5 & 370,5 & 1,16 & \\
\hline & Mínimo & 452,0 & 97,0 & 357,0 & 1,03 & \\
\hline & Máximo & 546,0 & 164,0 & 384,0 & 1,30 & \\
\hline & $\mathrm{Dp}$ & 66,46 & 47,37 & 19,09 & 0,19 & \\
\hline \multirow[t]{5}{*}{ Gleissolo } & Média & 482,81 & 67,06 & 450,12 & 1,31 & Argilosa \\
\hline & Mediana & 544,0 & 67,0 & 417,0 & 1,28 & \\
\hline & Mínimo & 124,0 & 24,0 & 132,0 & 0,98 & \\
\hline & Máximo & 789,0 & 102,0 & 819,0 & 1,63 & \\
\hline & $\mathrm{Dp}$ & 268,76 & 21,28 & 264,60 & 0,21 & \\
\hline \multirow[t]{5}{*}{ Neossolo } & Média & 734,5 & 51,0 & 214,5 & 1,46 & Média \\
\hline & Mediana & 734,5 & 51,0 & 214,5 & 1,46 & \\
\hline & Mínimo & 729,0 & 35,0 & 204,0 & 1,44 & \\
\hline & Máximo & 740,0 & 67,0 & 225,0 & 1,49 & \\
\hline & $\mathrm{Dp}$ & 7,77 & 22,62 & 14,89 & 0,03 & \\
\hline \multirow[t]{5}{*}{ Planossolo } & Média & 152,5 & 347,0 & 500,5 & 1,0 & Argilosa \\
\hline & Mediana & 142,5 & 345,5 & 494,5 & 1,0 & \\
\hline & Mínimo & 82,0 & 269,0 & 488,0 & 0,8 & \\
\hline & Máximo & 243,0 & 428,0 & 525,0 & 1,3 & \\
\hline & $\mathrm{Dp}$ & 73,42 & 76,92 & 17,01 & 0,20 & \\
\hline
\end{tabular}

(1) Fonte: Embrapa (2013).

A densidade do solo (Ds) está intimamente relacionada à granulometria do solo, ao teor de carbono orgânico e as características mineralógicas (REICHERT et al., 2009; KELLER et al., 2010), sendo um importante atributo físico, utilizado em conjunto com outros atributos, como um indicador da qualidade do solo (HÅKANSSON et al. 2000).

Pode-se observar valores médios para a Ds entre 1,0 a 1,46 $\mathrm{g} \mathrm{dm}^{-3}$ na camada superficial $(0,0-0,10$ m), sendo a maior média observada em área de Neossolo não passível de inundação, os quais apresentaram maiores teores de areia (Tabela 1). O predomínio da fração areia é característica geral dos Neossolos, os quais apresentam pequena expressão de atuação dos processos pedogenéticos, insuficiente para provocar modificações expressivas do material de origem, em razão da sua resistência ao intemperismo (SANTOS et al., 2012). Solos com maiores teores de areia tendem apresentar densidade superior em relação aos solos 
argilosos, enquanto solos com maiores teores de silte tendem apresentar densidade intermediária (BUENO et al., 1998; LIBARDI, 2005).

Cardoso et al. (2010) verificaram em áreas distintas (floresta nativa livre de inundação e pastagens nativas somente inundadas em cheias grandes proporções) do Pantanal da Nhecolândia com presença de Neossolo e classe textural areia, valores de Ds na camada superficial do solo $(0-10 \mathrm{~cm})$ igual a $1,40 \mathrm{~g} \mathrm{dm}^{-3}$ (área de floresta nativa), 1,45 e 1,57 $\mathrm{g} \mathrm{dm}^{-3}$ (áreas com pastagens nativas sem pastejo).

$\mathrm{O}$ pH em $\mathrm{H}_{2} \mathrm{O}$, apresentou variação de 4,6 a 5,5 (Tabela 2), sendo assim, respectivamente classificados como solos de $\mathrm{pH}$ em $\mathrm{H}_{2} \mathrm{O}$ baixo a médio (RIBEIRO et al., 1999). Verifica-se a predominância de baixo pH em $\mathrm{H}_{2} \mathrm{O}$ na maioria dos solos das áreas em estudo, com exceção para área de Neossolo, a qual apresentou maiores teores de bases trocáveis, em especial o $\mathrm{Ca}^{2+}$ e ausência de $\mathrm{Al}^{3+}$ trocável (Tabela 2). Sob condições de baixo $\mathrm{pH}$, as plantas não encontram a melhor disponibilidade de nutrientes nos solos, dificultando assim a absorção dos mesmos.

Coringa et al. (2012) observaram redução do $\mathrm{pH}$ em $\mathrm{H}_{2} \mathrm{O}$, com valores médios entre 4,3 a 5,3 nas camadas de solos (Planossolo, Gleissolo e Plintossolo) em áreas do Pantanal norte matogrosse. Cardoso et al. (2016) constataram valores médios de pH em $\mathrm{H}_{2} \mathrm{O}$ entre 4,7 a 6,6 em camadas superficiais de Neossolos em áreas do Pantanal na sub-região da Nhecolândia.

A acidez trocável $\left(\mathrm{Al}^{3+}\right)$ apresentou teor médio superior em áreas com presença de Planossolo (Tabela 2), sendo assim classificada como muito alto (RIBEIRO et al., 1999). A saturação por alumínio (m) apresentou teor médio superior na área de Argissolo (Tabela 2), sendo classificada como média (RIBEIRO et al., 1999). Solos sob condições de baixo pH tendem a apresentar uma rápida remoção de bases, maior liberação de íons de $\mathrm{Al}^{3+}$ aumentando a saturação por alumínio (PRIMAVESI, 2006). Mello et al. (2015) verificaram teores médios de acidez trocável $\left(\mathrm{Al}^{3+}\right)$ entre 0,6 a $1,4 \mathrm{cmol}_{\mathrm{c}} \mathrm{dm}^{-3}$ em áreas com presença de Gleissolo e Planossolo no Pantanal norte matogrossense.

$\mathrm{Na}$ área com presença de Neossolo (livre de inundação), verificou-se valores referentes a zero para acidez trocável $\left(\mathrm{Al}^{3+}\right)$ e saturação por aluminio $(\mathrm{m})$, e a acidez potencial $(\mathrm{H}+\mathrm{Al})$ foi inferior em relação as outras áreas amostradas (Tabela 2). Áreas livres de inundação tendem apresentar melhorias na qualidade química do solo, em decorrência da menor participação efetiva do processo de lixiviação na eliminação gradual dos cátions bivalentes $\left(\mathrm{Ca}^{2+}\right.$ e $\left.\mathrm{Mg}^{2+}\right)$ do complexo de troca.

A ausência de acidez trocável $\left(\mathrm{Al}^{3+}\right)$ e saturação por aluminio $(\mathrm{m})$ nesta área de Neossolo, com presença de cátions bivalentes em especial o $\mathrm{Ca}^{2+}$ em maior teor no solo e maior teor de matéria orgânica, pode ser em consequência da complexação do $\mathrm{Al}^{3+}$ por compostos orgânicos. Cardoso et al. (2016) verificaram ausência de $\mathrm{Al}^{3+}$ e menor acidez potencial, representada apenas por íons de $\mathrm{H}^{+}$em camadas superficiais de Neossolos em áreas do Pantanal na sub-região da Nhecolândia.

A acidez potencial ( $\mathrm{H}+\mathrm{Al}$ ) apresentou maior teor médio em áreas de Planossolo e menor teor em área de Neossolo (Tabela 2). Nas áreas de Planossolo a acidez potencial (H+Al) é classificada como alta, e para o Neossolo é classificada como média (RIBEIRO et al., 1999). Santos et al. (2013) verificaram acidez potencial $(\mathrm{H}+\mathrm{Al})$ muito alta nas camadas da maioria dos solos analisados em barrancos das margens do rio Paraguai. 
A capacidade de troca de cátions (CTC) tem grande importância na fertilidade do solo, pois está ligada aos teores de cátions trocáveis. A CTC ${ }_{\mathrm{pH} 7,0}(\mathrm{~T})$ e a CTC efetiva ( $\mathrm{t}$ ) apresentaram teores superiores em áreas com presença de Planossolo e inferiores em área de Argissolo (Tabela 2), sendo respectivamente classificadas como alta e muito alta (RIBEIRO et al., 1999), o que implica na maior capacidade desses solos em reter nutrientes.

Os teores médios de M.O. (Tabela 2), foram maiores em área de Neossolo e menores em área de Argissolo, sendo assim, classificados como alto para o Neossolo e baixo para o Argissolo (SOUSA et al., 2004). O maior teor médio de M.O. verificado na área de Neossolo pode ser em decorrência dessa área ser livre de inundação, o que impede a retirada constante de sedimentos das margens, depositando em outros locais. De acordo com Souza et al. (2007), baixos teores de matéria orgânica em solos do Pantanal podem estar ligados à erosão, transporte e deposição de materiais, que ocorrem em áreas sujeitas a inundação.

Santos et al. (2013) observaram teores de M.O. entre 0,55 a 1,33 $\mathrm{g} \mathrm{kg}^{-1} \mathrm{em}$ horizontes superficiais de barrancos as margens do rio Paraguai. Mello et al. (2015) verificaram em áreas alagáveis com presença de Gleissolo e Planossolo no Pantanal norte matogrossense, teores de M.O. entre $11 \mathrm{~g} \mathrm{~kg}^{-1} \pm 5$ (média e Dp) a $41 \mathrm{~g} \mathrm{~kg}^{-1} \pm 11$ (média e Dp). A soma de base (SB) apresentou menor teor em área de Argissolo, sendo igual a $3,35 \mathrm{cmol}_{\mathrm{c}} \mathrm{dm}^{-3}$ (média) e maior teor em áreas de Planossolo, igual a $11,4 \mathrm{cmol}_{\mathrm{c}} \mathrm{dm}^{-3}$ (média), sendo assim, classificadas como média e muito alta (RIBEIRO et al., 1999).

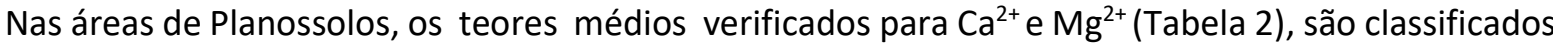
como muito altos; para o $\mathrm{K}^{+}$é classificado como médio (RIBEIRO et al., 1999). Apesar disso, nesse solo, em média a porcentagem de $\mathrm{Ca}^{2+}$ na $\mathrm{CTC}_{\mathrm{pH} 7,0}$ é igual a $32 \%$, enquanto a de $\mathrm{Mg}^{2+}$ é de $29 \%$. Assim, a relação entre esses dois nutrientes é estreita, sendo que, Sousa et al. (2004) consideram adequadas uma relação Ca:Mg entre 2 e 10. Por outro lado, a porcentagem de $\mathrm{K}^{+}$na $\mathrm{CTC}_{\mathrm{pH} 7,0}$ é de $0,9 \%$, muito baixa, embora os teores absolutos possam ser considerados adequados (SOUSA et al., 2004). Ainda segundo esses autores, idealmente o $\mathrm{K}^{+}$deveria ocupar $3 \%$ da $\mathrm{CTC}_{\mathrm{pH} 7,0}$.

Ressalta-se que embora a vegetação nativa esteja adaptada a essa situação, essas informações são uteis para o caso da necessidade de recomposição da mata ciliar, escassa em alguns pontos as margens do rio Paraguai. Os elevados teores verificados para $\mathrm{Ca}^{2+} \mathrm{e} \mathrm{Mg}^{2+}$ nas áreas de Planossolo, podem ser decorrentes dos processo de intemperismo e/ou remoção desses elementos de modo especial do substrato rochoso da Província Serrana (arenito da Formação Raizama e calcário da Formação Araras) do entorno, os quais são transportados e posteriormente acumulados na camada superficial do solo em pontos de baixa altitude, em decorrência da alternância natural do periodo de cheia e seca no Pantanal.

A saturação por bases (V) é um excelente indicativo das condições gerais de fertilidade dos solos. $\mathrm{Na}$ área de Neossolo verificou-se média de $71,9 \%$ para saturação de base (V), sendo classificada como alta. Porém, na área de Argissolo verificou-se média de 35,75\% para saturação de base (V), sendo classificada como baixa (RIBEIRO et al., 1999), solos distróficos (pouco férteis).

$\mathrm{O}$ baixo indice de saturação de bases $(\mathrm{V})$ na área de Argissolo, a qual apresenta $\mathrm{pH}$ em $\mathrm{H}_{2} \mathrm{O}$ baixo, significa que há menores quantidades de cátions $\left(\mathrm{Ca}^{2+}, \mathrm{Mg}^{2+} \mathrm{e} \mathrm{K}^{+}\right)$, saturando as cargas negativas dos coloides 
do solo, as quais em sua maioria estão sendo ocupada por $\mathrm{H}^{+}$e $\mathrm{Al}^{3+}$. Sob essas condições verifica-se restrições ao desenvolvimento das plantas. Em ambientes cultiváveis, quando no solo é obtido valor de saturação por base (V) entre 50 a $80 \%$ e pH entre 6,0 a 6,5 as culturas apresentam boa produtividade (RONQUIM, 2010).

Tabela 2: Estatística descritiva referente aos resultados das análises químicas dos solos de áreas de vegetação nativa as margens do rio Paraguai, Pantanal de Cáceres/MT.

\begin{tabular}{|c|c|c|c|c|c|c|c|c|c|c|}
\hline & & $\mathrm{pH}\left(\mathrm{H}_{2} \mathrm{O}\right)$ & $\mathrm{pH}$ SMP & $\mathbf{P}$ & \multicolumn{2}{|l|}{$\mathrm{K}^{+}$} & $\mathrm{Mg}^{2+}$ & $\mathrm{Al}^{3+}$ & $\mathrm{H}+\mathrm{Al}$ & SB \\
\hline & & & & \multicolumn{2}{|c|}{$\left(\mathrm{mg} \mathrm{dm}^{-3}\right)$} & \multicolumn{5}{|c|}{$\left.-{ }^{\prime}-\mathrm{cmol}_{\mathrm{c}} \mathrm{dm}^{-3}\right)$} \\
\hline \multirow[t]{5}{*}{ Argissolo } & Média & 4,6 & 5,7 & 12,15 & 49,0 & 2,25 & 1,0 & 2,35 & 5,75 & 3,35 \\
\hline & Mediana & 4,6 & 5,7 & 12,15 & 49,0 & 2,25 & 1,0 & 2,35 & 5,75 & 3,35 \\
\hline & Mínimo & 4,6 & 5,6 & 11,00 & 46,0 & 1,40 & 0,7 & 2,20 & 5,50 & 2,20 \\
\hline & Máximo & 4,6 & 5,8 & 13,30 & 52,0 & 3,10 & 1,3 & 2,50 & 6,00 & 4,50 \\
\hline & $\mathrm{Dp}$ & 0 & 0,14 & 1,62 & 4,24 & 1,20 & 0,42 & 0,21 & 0,35 & 1,62 \\
\hline \multirow[t]{5}{*}{ Gleissolo } & Média & 4,7 & 5,5 & 12,89 & 53,13 & 3,62 & 1,65 & 2,88 & 5,83 & 5,42 \\
\hline & Mediana & 4,7 & 5,5 & 12,45 & 44,5 & 2,60 & 1,25 & 3,15 & 6,15 & 3,95 \\
\hline & Mínimo & 4,5 & 4,8 & 5,40 & \multicolumn{2}{|l|}{23,0} & 0,30 & 0,60 & 1,90 & 1,10 \\
\hline & Máximo & 5,0 & 6,7 & 19,30 & 114,0 & 10,30 & 3,20 & 4,90 & 9,90 & 13,20 \\
\hline & $\mathrm{Dp}$ & 0,14 & 0,61 & 3,88 & 26,6 & 2,59 & 1,02 & 1,30 & 2,43 & 3,54 \\
\hline \multirow[t]{5}{*}{ Neossolo } & Média & 5,5 & 6,4 & 128,85 & \multicolumn{2}{|l|}{177,0} & 1,45 & 0,0 & 3,65 & 9,5 \\
\hline & Mediana & 5,5 & 6,4 & 128,85 & 177,0 & 7,6 & 1,45 & 0,0 & 3,65 & 9,5 \\
\hline & Mínimo & 5,3 & 6,4 & 64,10 & 99,0 & 6,2 & 1,30 & 0,0 & 3,5 & 7,8 \\
\hline & Máximo & 5,6 & 6,4 & 193,60 & 255,0 & 9,0 & 1,60 & 0,0 & 3,8 & 11,3 \\
\hline & $\mathrm{Dp}$ & 0,21 & 0 & 91,57 & \multicolumn{2}{|l|}{110,3} & 0,21 & 0,0 & 0,21 & 2,47 \\
\hline Planossolo & Média & 4,9 & 5,1 & 11,70 & 63,5 & 6,1 & 5,2 & 3,1 & 6,5 & 11,4 \\
\hline & Mediana & 5,0 & 5,3 & 8,60 & 58,0 & 5,8 & 4,9 & 2,2 & 6,4 & 10,8 \\
\hline & Mínimo & 4,6 & 4,4 & 5,90 & 47,0 & 2,5 & 3,3 & 1,3 & 4,1 & 5,9 \\
\hline & Máximo & 5,0 & 5,6 & 23,60 & 91,0 & 10,4 & 7,8 & 6,7 & 8,9 & 18,4 \\
\hline & Dp & 0,2 & 0,55 & 8,15 & 20,42 & 3,45 & 1,93 & 2,48 & 1,96 & 5,21 \\
\hline & & & & & & & & & & \\
\hline & & $T$ & $t$ & $\mathbf{v}$ & $m$ & M.O. & & & & \\
\hline & & $\left(\mathrm{cmol}_{\mathrm{c}} \mathrm{dm}\right.$ & & --- & --- & $\left(\mathrm{g} \mathrm{dm}^{-3}\right)$ & & & & \\
\hline Argissolo & Média & 9,10 & 5,7 & 35,75 & 42,85 & 16,85 & & & & \\
\hline & Mediana & 9,10 & 5,7 & 35,75 & 42,85 & 16,85 & & & & \\
\hline & Mínimo & 7,70 & 4,4 & 28,60 & 35,71 & 16,70 & & & & \\
\hline & Máximo & 10,50 & 7,0 & 42,90 & 50,00 & 17,00 & & & & \\
\hline & $\mathrm{Dp}$ & 1,97 & 1,83 & 10,11 & 10,10 & 0,21 & & & & \\
\hline Gleissolo & Média & 11,25 & 8,3 & 46,03 & 37,74 & 18,08 & & & & \\
\hline & Mediana & 9,65 & 7,1 & 52,3 & 29,67 & 19,60 & & & & \\
\hline & Mínimo & 4,90 & 3,6 & 12,5 & 14,29 & 8,30 & & & & \\
\hline & Máximo & 22,60 & 17,5 & 61,2 & 76,60 & 28,20 & & & & \\
\hline & Dp & 5,39 & 4,17 & 15,50 & 19,94 & 6,88 & & & & \\
\hline Neossolo & Média & 13,15 & 9,5 & 71,9 & 0,0 & 31,45 & & & & \\
\hline & Mediana & 13,15 & 9,5 & 71,9 & 0,0 & 31,45 & & & & \\
\hline & Mínimo & 11,3 & 7,8 & 69,0 & 0,0 & 25,7 & & & & \\
\hline & Máximo & 15,1 & 11,3 & 74,8 & 0,0 & 37,2 & & & & \\
\hline & $\mathrm{Dp}$ & 2,68 & 2,47 & 4,10 & 0,0 & 8,13 & & & & \\
\hline Planossolo & Média & 17,9 & 14,5 & 62,3 & 23,3 & 18,9 & & & & \\
\hline & Mediana & 16,0 & 13,0 & 67,5 & 16,0 & 18,7 & & & & \\
\hline & Mínimo & 14,8 & 12,6 & 39,9 & 8,0 & 14,4 & & & & \\
\hline & Máximo & 24,9 & 20,0 & 74,1 & 53,2 & 23,8 & & & & \\
\hline & $\mathrm{Dp}$ & 4,68 & 3,62 & 16,09 & 20,85 & 4,26 & & & & \\
\hline
\end{tabular}

- $\mathrm{pH}\left(\mathrm{H}_{2} \mathrm{O}\right)$ : Potencial de hidrogênio em água; P: Fosforo; $\mathrm{K}^{+:}$Potássio; $\mathrm{Ca}^{2+:}$ Cálcio; $\mathrm{Mg}^{2+:}$ Magnésio; Al ${ }^{3+:}$ Acidez trocável; $\mathrm{H+Al}$ : Acidez potencial; $\mathrm{SB}$ : Soma de bases $=\mathrm{Ca}^{2+}+\mathrm{Mg}^{2+}+\mathrm{K}^{+}$

- $\mathrm{T}$ : Capacidade de troca de cátion a $\mathrm{pH}_{7,0}=\mathrm{SB}+\left(\mathrm{H}^{+}+\mathrm{Al}^{3+}\right)$; - t: Capacidade de troca de cátion efetiva $=\mathrm{Al}^{3+}+\mathrm{Ca}^{2+}+\mathrm{Mg}^{2+}+\mathrm{K}^{+} ;-\mathrm{V}$ : Saturação por bases $=(\mathrm{SB} / \mathrm{T}) \times 100$; - m: Saturação por alumínio $=100 \times \mathrm{Al}^{3+} / \mathrm{t}$; - M.O.: Matéria orgânica. 
Santos et al. (2013) verificaram teores de saturação por bases (V) entre 19,34 a 46,74 nas camadas dos solos as margens do rio Paraguai. Coringa et al. (2012) relatam que variações encontradas para os valores da saturação de base (V) em solos do Pantanal indicam a presença de diferentes níveis de hidromorfismo, além da presença de descontinuidades sedimentológicas no ambiente.

Mesmo verificando-se teores médios a altos para saturação por base (V) para maior parte dos solos das áreas de estudo, pode-se observar a ocorrencia de acidez potencial variando de 3,6 a $6,5 \mathrm{cmol}_{\mathrm{c}} \mathrm{dm}^{-3}$, sendo respectivamente classificada de média a alta (RIBEIRO et al., 1999) e alta saturação por $\mathrm{Al}^{3+}$, exceto para Neossolo. Com base nos resultados de $\mathrm{H}+\mathrm{Al}$, verifica-se que os cátions básicos ocupam $64 \%$ da $\mathrm{CTC}_{\mathrm{pH} 7,0}$ em Argissolo; $54 \%$ em Gleissolo; 28\% em Neossolo e 38\% em Planossolo. Valores elevados de acidez potencial favorecem a lixiviação de cátions básicos, tais como $\mathrm{Ca}^{2+}, \mathrm{Mg}^{2+} \mathrm{e} \mathrm{K}^{+}$.

Pode-se observar na área com presença de Neossolo, maiores teores de $\mathrm{P}$ e $\mathrm{K}^{+}$(Tabela 2), sendo classificados como muito alto (RIBEIRO et al., 1999). Os elevados teores de P e K+ para área de Neossolo, podem ser provenientes da ciclagem de nutrientes nessa área com presença de vegetação arbórea, a qual apresenta elevado teor de materia orgânica (Tabela 2). A matéria orgânica assume papel relevante na reciclagem de nutrientes, sendo que, o processo de decomposição e mineralização constitui provavelmente a principal fonte de nutrientes para as plantas em ecossistemas de baixa fertilidade natural e não fertilizados (MOREIRA et al., 2004), como é o caso do Pantanal.

Sousa et al. (2015) verificaram em camadas superficial do solo as margens do rio Paraguai, teores mais elevados de P e K em área de Neossolo com presença de vegetação arbórea exuberante, pressupondo uma eficiente ciclagem desses elementos, decorrentes do maior aporte de material orgânico. Através dos resultados obtidos nas áreas amostradas, pode-se verificar média igual a 5,6 para o $\mathrm{pH}$ SMP, com valores variando de 4,4 em área de Planossolo a 6,7 em área de Gleissolo. A acidez potencial ( $\mathrm{H}+\mathrm{Al}$ ) determinada pelo método do acetato de cálcio tamponado a $\mathrm{pH}_{7,0}$ apresentou teor médio igual a $5,75 \mathrm{cmol}_{\mathrm{c}} \mathrm{dm}^{-3}$, com valores variando de 1,9 a 9,9 $\mathrm{cmol}_{\mathrm{c}} \mathrm{dm}^{-3}$ em áreas de Gleissolo. Almeida Junior; Nascimento; Barros (2015) obtiveram resultados semelhantes em relação aos valores do $\mathrm{pH}$ SMP, os quais variaram de 4,41 a 7,12 para as várias regiões e classes de solos do Estado da Paraíba.

A relação verificada entre os valores da acidez potencial $(\mathrm{H}+\mathrm{Al})$ e do $\mathrm{pH}$ sMP é descrita de forma significativa apresentando coeficiente de determinação $\left(R^{2}=0,86\right)$, sendo que, a equação $H+A l=24,1861$ $3,3144 \times \mathrm{pH}$ SMP, poderá ser usada para estimar a acidez potencial a partir dos valores de $\mathrm{pH}$ SMP entre 4,4 a 6,7 para solos dessas áreas. Estatisticamente, pode-se evidenciar que a acidez potencial (H+Al) e o pH smp apresentaram correlação significativa $(p \leq 0,05)$ de forma negativa $(r=-0,93)$, isto é, o aumento dos teores de acidez potencial resultou na diminuição nos valores do pH SMP (Figura 2). 


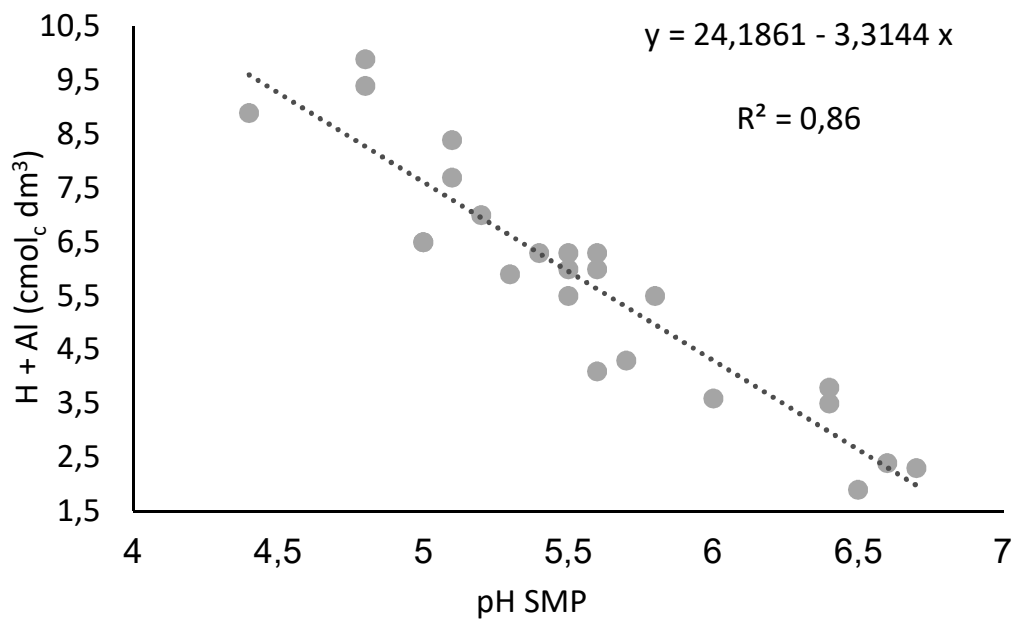

Figura 2: Relação entre a acidez potencial $(\mathrm{H}+\mathrm{Al})$ pelo método do acetato de cálcio tamponado a pH 7,0 e o pH sMP em solos de áreas de vegetação nativa as margens do rio Paraguai, Pantanal de Cáceres//MT.

\section{CONCLUSÕES}

Os solos apresentaram na maioria das áreas baixa fertilidade natural e acidez trocável elevada, proporcionando restrições ao crescimento e desenvolvimento das plantas as margens do rio. Nas áreas onde constatou-se maior teor de areia nos solos verificou-se densidade mais elevada. $\mathrm{A}$ partir da equação $\mathrm{H}+\mathrm{Al}=$ $24,1861-3,3144 \times \mathrm{pH}$ SMP $\left(R^{2}=0,86\right)$, poderá ser estimada a acidez potencial para os solos dessas áreas com valores de $\mathrm{pH}$ sMp entre 4,4 a 6,7.

AGRADECIMENTOS: À Fundação de Amparo à Pesquisa do Estado de Mato Grosso - FAPEMAT pela concessão de bolsa de estudo durante o mestrado ao primeiro autor; ao ICMBIO - Estação Ecológica de Taiamã pela autorização concedida para realização de atividade com finalidade científica.

\section{REFERÊNCIAS}

ALMEIDA JUNIOR, A. B.; NASCIMENTO, C. W.A.; BARROS, F. M. R.. Acidez potencial estimada pelo método do $\mathrm{pH}$ SMP em solos do estado da Paraíba. Revista Brasileira de Ciência do Solo, v.39, n.3, p.767-773, 2015. DOI:

http://dx.doi.org/10.1590/01000683rbcs20140307

ANDREWS, S. S.; KARLEN, D. L.; MITCHELL, J. P.. A comparison of soil quality indexing methods for vegetable production systems in Northern California. Agriculture, Ecosystems and Environment, v.90, p.25-45, 2002. DOI: http://doi.org/10.1016/S0167-8809(01)00174-8

BUENO, B. S.; VILAR, O. M.. Mecânica dos solos. São Carlos: USP/EESC, 1998.

CARDOSO, E. L.; SILVA, M. L. N.; SILVA, C. A.; CURI, N.; FREITAS, D. A. F.. Estoques de carbono e nitrogênio em solo sob florestas nativas e pastagens no bioma Pantanal. Pesquisa Agropecuária Brasileira, v.45, n.9, p.1028-1035, 2010. DOI: http://dx.doi.org/10.1590/S0100$\underline{\text { 204X2010000900013 }}$

CARDOSO, E. L.; SANTOS, S. A.; URBANETZ, C.; CARVALHO FILHO, A.; NAIME, U. J.; SILVA, M. L. N.; CURI, N.. Relação entre solos e unidades de paisagem no ecossistema Pantanal. Pesquisa Agropecuária Brasileira, v.51, n.9, p.1231-1240, 2016. DOI: http://dx.doi.org/10.1590/s0100$\underline{204 \times 2016000900023}$

CARVALHO JUNIOR, W.; CHAGAS, C. S.; LAGACHEIRE, P.; CALDERANO FILHO, B.; BHERING, S. B.. Evaluation of statistical and geostatistical models of digital soil properties mapping in tropical mountain regions. Revista Brasileira de Ciências do Solo, v.38, v.3, p.706-717, 2014. DOI: http://dx.doi.org/10.1590/\$0100-06832014000300003

CORINGA, E. A. O.; COUTO, E. G.; TORRADO, P. V..

Geoquímica de solos do Pantanal Norte, Mato Grosso. Revista Brasileira de Ciência do Solo, v.38, n.3, p.1784-1793, 2014. DOI: http://dx.doi.org/10.1590/S0100$\underline{06832014000600013}$

CORINGA, E. A. O.; COUTO, E. G.; PEREZ, X. L. O.; TORRADO, P. V.. Atributos de solos hidromórficos no Pantanal norte matogrossense. Acta Amazônica, v.42, n.1, p.19-28, 2012. DOI: http://dx.doi.org/10.1590/S0044-59672012000100003 
EMBRAPA. Manual de métodos de análises químicas de solos, plantas e fertilizantes. Rio de Janeiro: Embrapa Solos, 1999.

EMBRAPA. Manual de métodos de análises químicas de solos, plantas e fertilizantes. 2 ed. Brasília: Embrapa Informação Tecnológica, 2009.

EMBRAPA. Sistema brasileiro de classificação de Solos. 3 ed. Brasília: Embrapa, 2013.

FERNANDES, F. A.; FERNANDES, A. H. B. M.; SOARES, M. T. S; PELLEGRIN, L. A.; LIMA, I. B. T.. Atualização do mapa de solos da planície pantaneira para o sistema brasileiro de classificação de solos. Corumbá: Embrapa Pantanal, 2007.

HÅKANSSON, I.; LIPIEC, J.. A review of the usefulness of relative bulk density values in studies of soil structure and compaction. Soil and Tillage Research, v.53, n.2, p.71-85, 2000. DOI: https://doi.org/10.1016/S0167-1987(99)00095-1

HARRIS, M. B.; TOMAS, W.; MOURÃO, G.; SILVA, C. J.; GUIMARÃES, E.; SONODA, F.; FACHIM, E.. Safeguarding the Pantanal Wetlands: Threats and conservation initiatives. Conservation Biology, v.19, n.3, p.714-720, 2005. DOI: https://doi.org/10.1111/j.1523-1739.2005.00708.x

IBGE. Manual técnico da vegetação brasileira. 2 ed. Rio de Janeiro: IBGE, 2012.

IBGE; MMA. Instituto Brasileiro de Geografia e Estatística. Ministério do Meio Ambiente. Mapas temáticos. IBGE, 2010.

KAMPF, N.; CURI, N.. Formação e evolução do solo (pedogênese). Viçosa: Sociedade Brasileira de Ciências do Solo, 2012.

KEESSTRA, S. D.; GEISSEN, V.; MOSSE, K. P. M.; PIIRANEN, S.; SCUDIERO, E.; LEISTRA, M.; SCHAIK, L. V.. Soil as a filter for groundwater quality. Current Opinion in Environmental Sustainability, v.4, p.507-516, 2012. DOI: https://doi.org/10.1016/i.cosust.2012.10.007

KELLER, T.; HÅKANSSON, I.. Estimation of reference bulk density from soil particle size distribution and soil organic matter content. Geoderma, v.154, p.398-406, 2010. DOI: https://doi.org/10.1016/i.geoderma.2009.11.013

LIBARDI, P. L. .Dinâmica da água no solo. São Paulo: Edusp, 2005.

MELLO, J. M.; COUTO, E. G.; AMORIM, R. S.S .; CHIG, L.A .; JOHNSON, M. S.; LOBO, F. A.. Dinâmica dos atributos físicoquímicos e variação sazonal dos estoques de carbono no solo em diferentes fitofisionomias do Pantanal norte matogrossense. Revista Árvore, v.39, n.2, p.325-336, 2015. DOI: https://doi.org/10.1590/0100-67622015000200012

MOREIRA, A.; MALAVOLTA, E.. Dinâmica da matéria orgânica e da biomassa microbiana em solo submetido a diferentes sistemas de manejo na Amazônia Ocidental. Pesquisa Agropecuária Brasileira, v.39, n.11, p.1103-1110, 2004. DOI: http://dx.doi.org/10.1590/S0100-204X2004001100008

MULDER, V. L.; BRUIN, S.; SCHAEPMAN, M. E.; MAYR, T. R.. The use of remote sensing in soil and terrain mapping - a review. Geoderma, v.162, n.1-2, p.1-19, 2011. DOI: https://doi.org/10.1016/i.geoderma.2010.12.018

PRAGANA, R. B.; RIBEIRO, M. R.; NÓBREGA, J. C. A.; RIBEIRO FILHO, M. R.; COSTA, J. A.. Qualidade física de Latossolos Amarelos sob plantio direto na região do Cerrado piauiense. Revista Brasileira de Ciências do Solo, v.36, n.5, p.15911600, 2012. DOI: http://dx.doi.org/10.1590/S0100$\underline{06832012000500023}$

PRIMAVESI, A.. Manejo ecológico do solo: a agricultura em regiões tropicais. 18 ed. São Paulo: Nobel, 2006.

R DEVELOPMENT CORE TEAM. R: A language and environment for statistical computing. Vienna: $R$ Foundation for Statistical Computing, 2015.

RAIJ, B. V.; ANDRADE, J. C.; CANTARELLA, H.; QUAGGIO, J. A.. Análise química para avaliação da fertilidade de solos tropicais. Instituto Agronômico de Campinas, 2001.

RIBEIRO, A. C.; GUIMARÃES, P. T. G.; ALVAREZ, V. H.. Recomendações para o uso de corretivos e fertilizantes em Minas Gerais. Viçosa: Comissão de Fertilidade do Solo do Estado de Minas Gerais, 1999.

REICHERT, J. M.; SUZUKI, L. E. A. S.; REINERT, D. J.; HORN, R.; HÅKANSSON, I.. Reference bulk density and critical degree-of compactness for no-till crop production in subtropical highly weathered soils. Soil Tillage Research, v.102, n.2, p.242-254, 2009. DOI: https://doi.org/10.1016/j.still.2008.07.002

RONQUIM, C. C.. Conceitos de fertilidade do solo e manejo adequado para regiões tropicais. Campinas: Embrapa Monitoramento por Satélite, 2010.

SANTOS, F. A. S.; MARIANO, R. S. R.; PIERANGELI, M. A. P.; SOUZA, C. A.; BAMP, A. C.. Atributos físicos e químicos de solos das margens do rio Paraguai. Revista Ambiente \& Água, v.8, n.1, p.239-249, 2013. DOI: http://dx.doi.org/10.4136/ambi-agua.1009

SANTOS, J. C. B.; SOUZA JÚNIOR, V. S.; CORRÊA, M. M.; RIBEIRO, M. R.; ALMEIDA, M. C.; BORGES, L. E. P..

Caracterização de neossolos regolíticos da região semiárida do Estado de Pernambuco. Revista Brasileira Ciência do Solo, v.36, n.3, p.683-695, 2012. DOI: https://doi.org/10.1590/S0100-06832012000300001

SILVA, J. S. V.; ABDON, M. M.. Delimitação do Pantanal brasileiro e suas sub-regiões. Pesquisa Agropecuária Brasileira, v.33, n. especial, p.1703-1711, 1998.

SKORUPA, A. L. A.; GUILHERME, L. R. G.; CURI, N.; SILVA, C. P. C.; SCOLFORO, J. R. S.; MARQUES, J. J. G. S. M.. Propriedades de solos sob vegetação nativa em Minas Gerais: distribuição por fitofisionomia, hidrografia e variabilidade espacial. Revista Brasileira de Ciência do Solo, v.36, n.1, p.11-22, 2012. DOI: http://dx.doi.org/10.1590/S010006832012000100002

SOMMER, M.. Influence of soil pattern on matter transport in and from terrestrial biogeosystems - a new concept for landscape pedology. Geoderma, v.133, n1-2, p.107-123, 2006. DOI: http://dx.doi.org/10.1016/j.geoderma.2006.03.040 
SOUSA, D. M. G.; LOBATO, E.. Cerrado: correção do solo e adubação. 2 ed. Brasília: Embrapa Informação Tecnológica, 2004.

SOUSA, J. B.; PIERANGELI, M. A. P.; SERAFIM, M. E.; SOUZA, C. A.. Atributos morfológicos, físicos e químicos de solos e processos erosivos nas margens do rio Paraguai, Pantanal superior, Mato Grosso, Brasil. Boletim de Geografia, v.33, n.1, p.109-122, 2015. DOI:

http://dx.doi.org/10.4025/bolgeogr.v33i1.22580

SOUZA, C. A.; CUNHA, S. B.. Pantanal de Cáceres/MT: dinâmica das margens do rio Paraguai entre a cidade de Cáceres e a estação ecológica da ilha de Taiamã/MT. Revista Eletrônica da Associação dos Geógrafos Brasileiros, n.5, p.18-42, 2007.

A CBPC - Companhia Brasileira de Produção Científica (CNPJ: 11.221.422/0001-03) detém os direitos materiais desta publicação. Os direitos referem-se à publicação do trabalho em qualquer parte do mundo, incluindo os direitos às renovações, expansões e disseminações da contribuição, bem como outros direitos subsidiários. Todos os trabalhos publicados eletronicamente poderão posteriormente ser publicados em coletâneas impressas sob coordenação da Sustenere Publishing, da Companhia Brasileira de Produção Científica e seus parceiros autorizados. Os (as) autores (as) preservam os direitos autorais, mas não têm permissão para a publicação da contribuição em outro meio, impresso ou digital, em português ou em tradução. 